\title{
Chemicals in Reverse Osmosis-treated Wastewater: Occurrence, Health Risk, and Contribution to Residual Dissolved Organic Carbon
}

\section{Short title: Chemicals in RO-treated Wastewater: Occurrence, Risk, and DOC Contribution}

\author{
Kathryn L. Linge ${ }^{I}$, Palenque Blair ${ }^{2}$, Francesco Busetti ${ }^{1}$, Clemencia Rodriguez ${ }^{3}$, and Anna Heitz ${ }^{1}$ \\ ${ }^{1}$ Curtin Water Quality Research Centre, Department of Chemistry, Curtin University, GPO Box \\ U1987, Perth, Western Australia, 6845, Australia \\ ${ }^{2}$ Water Corporation, 629 Newcastle Street, Leederville, Perth, Western Australia 6007, Australia \\ ${ }^{3}$ Department of Health, Government of Western Australia. Grace Vaughan House 227 Stubbs \\ Terrace, Shenton Park, 6008, Western Australia, Australia
}

Corresponding Author:

Kathryn L Linge

Email: k.linge@curtin.edu.au

\begin{abstract}
The quality and safety of reverse osmosis (RO)-treated secondary wastewater, for indirect potable re-use, was assessed using a dataset of 375 chemicals measured in RO-treated wastewater. A screening health risk assessment indicated that four $N$-nitrosamines were of potential concern, although median concentrations of these chemicals were always below health values. The most frequently detected chemicals in RO-treated water were disinfection by-products, volatile organic compounds, metals and complexing agents, in contrast to many monitoring programs that focus on pharmaceuticals, personal care products and hormones. Frequent detections in RO-treated wastewater were most related to high concentrations in secondary wastewater, relative to limit of reporting, and the potential for chemicals to form or be added during the treatment process, rather than poor rejection by RO membranes. Between 3.7 and $10.7 \mu \mathrm{g} / \mathrm{L}$ of dissolved organic carbon (DOC) in RO permeate could be attributed from chemicals detected on at least one occasion, with the majority of this total attributed to chemicals detected in less than $25 \%$ of samples. While chemicals below detection may contribute a significant component of DOC, it is likely that natural organic matter and soluble microbial products still contribute the majority of DOC to RO permeate.
\end{abstract}


A high degree of safety is demonstrated for the use of RO-treated wastewater as an indirect source of potable water.

Key words | chemical risk, groundwater replenishment, indirect potable reuse, reverse osmosis, screening health risk assessment, water recycling

\section{ACRONYMS AND ABBREVIATIONS}

BPP: Beenyup Pilot Plant, DBP: disinfection by-product, DOC: dissolved organic carbon, DTPA: diethylenetriaminepentaacetic acid; EDTA: ethylenediaminetetraacetic acid, KWRP: Kwinana Water Recycling Plant, LOR: limit of reporting, MF: microfiltration, MW: molecular weight, NDBA: $N$-nitrosodi-n-bultyldiamine, NDMA: $N$-nitrosodimethylamine, NDPA: $N$-nitrosodi-npropylamine, NEMA: $N$-nitrosoethylmethylamine NMOR: $N$-nitroso-morpholine, NPIP: $N$ nitrosopiperidine, NTA: nitrilotriacetic acid, PDTA: propylenediaminetetraacetic acid, RO: reverse osmosis, TEQ: toxic equivalent, TTC: threshold of toxicological concern, VOC: volatile organic compound, WW: wastewater, WWTP: wastewater treatment plant

\section{INTRODUCTION}

Drinking water augmentation is still considered a high-risk use of recycled wastewater (WW). While pathogenic microorganisms remain the greatest risk to consumers of recycled water (AGWR 2008; ADWG 2011), secondary WW also contains many chemicals with a wide range of residential, industrial, and agricultural origins and uses (Shon et al. 2006; Van Buynder et al. 2009). Reverse osmosis (RO) membrane treatment is a key barrier for chemical removal (Bellona et al. 2004; Snyder et al. 2007) and RO treatment efficiency depends on chemical concentration and properties, membrane properties, as well as specific plant design and operation. While many studies of chemical rejection by RO membranes have been published (Agenson et al. 2003; Bellona et al. 2004), many are conducted at the laboratory-scale, using 'virgin' RO membranes, and may not be 
directly applicable to long-term, full-scale plant operation. Opportunities to produce a large chemical dataset for RO treated wastewater are limited, in part due to the difficulty and cost associated with the method development and analysis of large numbers of chemicals at trace and ultra-trace concentrations.

Residual dissolved organic carbon (DOC) remains in RO-treated WW, which may comprise of natural organic matter, soluble microbial products and trace concentration of anthropogenic chemicals (Shon et al. 2006). The bulk characteristics of DOC in RO permeate have been investigated using ion exchange (Fujita et al. 1996; Drewes et al. 2003), size exclusion chromatography with organic carbon and nitrogen detection (Henderson et al. 2010) and fluorescence excitation emission spectroscopy (Singh et al. 2009). These studies have shown that DOC in RO permeates do not normally contain organic material of molecular weight greater than $500 \mathrm{Da}$ (Drewes et al. 2003), and that, based on Amberlite XAD ${ }^{\mathrm{TM}}$ resin fractionation, up to $50 \%$ of DOC is hydrophilic (Fujita et al. 1996). Molecular weight fractions $<350$ Da form the major components of RO DOC (Henderson et al. 2010), with low molecular weight acids and neutrals contribution a significant component (Drewes et al. 2003). In some studies no humic acids have been detected in RO permeate (Fujita et al. 1996), although humic acids may penetrate RO membranes when treating RO concentrates with high DOC concentrations (Henderson et al. 2010). Ratios of $\mathrm{H}: \mathrm{C}$ and N:C are also typically higher in $\mathrm{RO}$ permeate than found in natural drinking waters (Fujita et al. 1996), also suggesting that RO DOC is non-humic. In the context of DOC characterisation, many anthropogenic chemicals are classed as low molecular weight neutral or acidic compounds. However, to date there has been no attempt to assess the contribution of anthropogenic chemicals to the DOC in RO.

An important component of achieving water re-use targets in Western Australia is augmentation of drinking water supplies through groundwater replenishment (Water Corporation 2009). In this paper 
we consider data from a large study of 375 compounds in secondary WW and recycled water produced by microfiltration (MF) and RO treatment (Van Buynder et al. 2009), and assess the quality and safety of RO-treated WW in the context of indirect potable water re-use via groundwater replenishment. To date, this dataset represents one of the most comprehensive analyses of recycled water quality worldwide. In addition, the dataset has been used to identify key factors contributing to frequent detection of a chemical in RO permeate, and estimate the contribution of anthropogenic chemicals to DOC in RO permeate.

\section{METHODOLOGY}

\section{Chemical selection, monitoring and analysis}

A total of 375 chemicals of potential health concern, in 13 different classes, were monitored (see Table 1 for a summary, and Supporting Information Tables S1-S15 for detailed information). Chemical selection was based on volume of use in Western Australia, level of toxicological concern, environmental persistence, existence of drinking water guidelines, and prior detection in WW as reported in the scientific literature (Rodriguez et al. 2007a; Rodriguez et al. 2007b). Chemicals for which analytical methods were not available in Australia were prioritised based on health risk, and chemicals with low health toxicity or less likely to be present in concentrations of health concern were excluded. Chemicals for which analytical method development would be difficult or not feasible during the timeframe of the project were also excluded.

Chemical monitoring was undertaken over 3 years, with full details previously published (Van Buynder et al. 2009; Linge et al. 2010). Reverse osmosis permeate from two MF/RO plants was tested; the Kwinana Water Recycling Plant (KWRP), a full-scale plant (17ML/day) producing water for industrial processes only, and the Beenyup Pilot Plant (BPP), a smaller plant ( $67 \mathrm{~kL} / \mathrm{day})$ constructed to test MF/RO treatment at Beenyup wastewater treatment plant (WWTP). As well as operating at different scales, the plants had different loadings of industrial-sourced WW, although 
both have low industrial loading by international standards (Van Buynder et al. 2009). Secondary treated WW was also characterised using samples from Perth's three main activated-sludge WWTPs, which treat $85 \%$ of the WW produced in the Perth metropolitan area, and this data has been reported elsewhere (Van Buynder et al. 2009; Rodriguez et al. 2010).

Sampling was carried out during seven approximately quarterly sampling events from December 2006 to October 2008 (Van Buynder et al. 2009; Rodriguez et al. 2010). Six sampling events were undertaken for all chemical classes, with an additional seventh sampling event undertaken for $N$ nitrosamines only. For most chemicals, samples were collected in every season of the year and on every day of the week over the course of the project.

The details of sampling and analytical procedures have been published previously (Van Buynder et al. 2009). Twenty-four-hour composite samples were collected using an automated and refrigerated ISCO 4700 sampler, except for unstable or volatile analytes, which were collected as grab samples. Sampling procedures aimed to optimise analyte preservation until analysis, and appropriate preservation agents were added to sample bottles prior to sample collection, or prior to sub-sample collection in the case of composite samples. Field and trip blanks were collected on each day of sampling, and replicate samples comprised $12 \%$ of all secondary WW samples and $8 \%$ of all RO permeate samples. A quality assurance program was implemented to ensure data quality. Analytical methods that were not accredited by the National Association of Testing Authorities, Australia (NATA) were scrutinised through appropriate peer review, and inter-laboratory testing was used in method validation where possible. In addition to concentration data, each laboratory calculated method uncertainty, limits of reporting, precision, and bias or accuracy for each method.

\section{Data analysis}


Over 20,000 analyses were conducted, not including field and trip blanks. The dataset was analysed after exclusion of trip blanks, field blanks and replicate samples, with chemical occurrence assessed by calculation of percentage detection frequency and median and maximum concentrations. Median was chosen rather than average because it is less affected by outliers and because most chemicals did not follow a normal distribution. Chemical classes were measured using a variety of analytical methods, each with different levels of sensitivity. For many analytes, the analytical limit of reporting (LOR) influenced percentage detection calculations and other statistics. Calculation of median concentrations incorporated all data points including samples reported to be below the LOR, and these were assumed to be equal to the LOR for the purposes of that calculation. While this conservative approach will overestimate the actual median concentration of chemicals reported below the LOR in more than $50 \%$ of samples, it was deemed appropriate given our primary goal of assessing the safety of RO-treated WW as potential potable water source.

All results were assessed against benchmark (non-effect) human health values, which were defined using the approach described by Rodriguez et al. (2007b). Chemicals were assigned to one of three categories: 1) chemicals with established regulatory guidelines, 2) unregulated chemicals with toxicity data sufficient for derivation of a health value, 3) unregulated chemicals without toxicity data. Health values for unregulated chemicals without toxicity data were derived using the concept of the threshold of toxicological concern (TTC) (Kroes et al. 2005). In the TTC, chemicals are allocated to a low, intermediate or high toxicity class, based on chemical structure. Health values for each toxicity class are derived from statistical analysis of a large chemical toxicology dataset, and are considered very conservative.

The screening health risk assessment of RO permeate used the concept of risk quotients (RQs) to compare health values to the concentration of each chemical, with $\mathrm{RQ}<1$ indicating that no health impacts were expected. $\mathrm{RQ}_{\max }$ was calculated using the maximum concentration measured for each 
chemical, while $R Q_{\text {med }}$ was calculated using the median concentration. In cases when a chemical was never detected, $\mathrm{RQ}_{\text {med }}$ was estimated using the average $\mathrm{LOR}$ as a worst case scenario. The exceptions to this approach were the risk assessments of polycyclic aromatic hydrocarbons (PAHs), and polychlorinated dibenzo-p-dioxins, polychlorinated dibenzofurans and dioxin-like poly chlorinated biphenyls. For these two classes, the concept of toxic equivalents (TEQ) was used, which expresses the toxicities of different chemicals on a common basis by comparing to a reference chemical. This is a widely accepted practice for both PAHs (Bruce et al. 2007) and dioxin-like compounds (Van den Berg et al. 2006), and the TEQ analysis for these classes are reported elsewhere (Rodriguez et al. 2008; Van Buynder et al. 2009).

The contribution to the residual DOC was estimated for each chemical with carbon incorporated in its molecular structure. Median and maximum DOC contributions were determined using previously calculated median and maximum concentrations, multiplied by the percentage carbon in each molecule. In cases where a chemical was never detected, median and maximum concentrations were estimated using half the average LOR and the average LOR, respectively. For comparison, total DOC was also determined on 15 occasions throughout the sampling program, with duplicate samples analysed on 2 occasions. Analyses were undertaken by a commercial organisation using a high-temperature combustion method based on Standard Method 5310 B (Clesceri et al. 1998), with a reported LOR of $0.2 \mathrm{mg} / \mathrm{L}$.

\section{RESULTS AND DISCUSSION}

\section{Occurrence of chemicals in RO permeate}

Of the 375 chemicals analysed, 108 (29\%) were detected at least once in RO permeate (Table 1), although 42 chemicals were only detected on one occasion, typically at concentrations close to the LOR. Only 29 chemicals (8\%) had percentage detection in RO permeate greater than $25 \%$ (Table 2, percentage detections for all chemicals in Supporting Information Tables S1-S15). Eight of these 
chemicals were classed as disinfection by-products (DBPs), including 7 halogenated DBPs, $1 \mathrm{~N}$ nitrosamine, and 1 inorganic DBP, 8 were classed as volatile organic compounds (VOCs), 6 were metals or metalloids, and the remaining were classed as complexing agents, phenols, or miscellaneous organic chemicals. Analysis of these most frequently detected chemicals indicated several factors that contribute to higher frequency of detection in RO permeate, other than poor rejection through RO membranes. Firstly detection in RO permeate may simply indicate that the chemical's occurrence in secondary WW is high relative to the LOR achievable for RO permeate analysis, even when RO rejection is high. High frequency of detection may also be related to factors within the MF/RO treatment process that lead to formation or even addition of some chemicals during treatment, as described below.

Examples of chemicals frequently detected in RO permeate because of high detections in secondary WW include the metals and metaloids (B, Cu, Li, Si, Sr, $\mathrm{Zn})$ and the complexing agents (ethylenediaminetetraacetic acid [EDTA] and nitrilotriacetic acid [NTA]), which were typically measured in secondary WW at concentrations between 8 and 1700 times the LOR. Thus, while RO removal was consistently better than $90 \%$ except for boron (Van Buynder et al. 2009), frequent detections at low concentrations were still recorded in RO permeate. Metals are sourced from both urban and industrial catchments, and frequent detections in secondary WW are often related to incomplete removal during WW treatment as well as very high concentrations in influent wastewater (Busetti et al. 2005; Choubert et al. 2011). Complexing agents are also used broadly, poorly removed by conventional WWTPs (Oviedo and Rodriguez 2003), and commonly detected in $\mu \mathrm{g} / \mathrm{L}$-concentrations in secondary WW (Reemtsma et al. 2006). Another chemical that was always detected in secondary WW was 1,4-dioxane, which is also widely used and not significantly removed in conventional WWTP (Zenker et al. 2003). However, variable RO rejection of 1,4dioxane (Van Buynder et al. 2009) also contributes to the high frequency of detection in RO 
permeate. Poor rejection of 1,4-dioxane is predicted because it is a small (molecular weight $[\mathrm{MW}]=$ 88 Da), neutral and hydrophilic molecule (Bellona et al. 2004).

In contrast to metals and complexing agents, DBPs were often more frequently detected in RO permeate than in secondary WW. As part of the MF/RO process, it is standard practice to chloraminate WW before MF to minimise RO membrane fouling (Bartels et al. 2005). Chlorine dosed before MF reacts with ammonia present in, or added to, the WW to form monochloramine, and this process is recognised to cause additional formation of some DBPs (Van Buynder et al. 2009; Farre et al. 2011). The phenol 2,4-dichlorophenol and the VOC chloromethane, also classed as a DBP (Krasner et al. 2006), also showed similar increases in concentration during MF/RO (Van Buynder et al. 2009), and chloramination may also play role in the frequent detection of these compounds in RO permeate. Thus for some chemicals, mitigation may be best achieved though treatment optimisation, rather than just relying on removal by RO.

In contrast to the organic DBPs, chlorate is commonly present in concentrated hypochlorite solutions (Bolyard et al. 1992). Thus chlorate is effectively added during MF/RO treatment during disinfection. This hypothesis is further supported by comparison of the overall treatment efficiency of the MF/RO for chlorate (76\%) to the treatment efficiency for RO alone (95\%) (Van Buynder et al. 2009). Reverse osmosis removal of anions is expected to be high because they are negatively charged and repelled from the negatively charged RO membrane (Bellona et al. 2004). It is noted that chlorite and bromate can also be present in hypochlorite solutions (depending on its purity), although at lower concentrations (Bolyard et al. 1992).

Addition during the treatment process is also hypothesised to occur for both acrylonitrile and bisphenol A. The median concentration of acrylonitrile in RO permeate $(0.13 \mu \mathrm{g} / \mathrm{L})$ was higher than that in secondary WW $(0.04 \mu \mathrm{g} / \mathrm{L})$, and percentage detections in RO permeate $(83 \%)$ were also 
higher than in secondary WW (50\%). Acrylonitrile can be used in the production of both RO and MF membranes (Nasef and Hegazy 2004), and therefore it is likely that the concentrations measured in RO permeate are due to acrylonitrile leaching from the treatment membranes. No measurements of acrylonitrile were made at sampling points between the MF and RO membranes and therefore it is not possible to determine whether the elevated concentrations seen in RO permeate compared are from the RO or MF membranes. At BPP, the MF membrane is made from polyvinylidene fluoride (PVDF), while the RO membrane is a composite polyamide, and the acrylonitrile is more likely to result from the RO membrane (Nasef and Hegazy 2004). At KWRP, both membranes are made from composite polyamide and therefore either could cause elevated acrylonitrile concentrations. Further sampling and analysis is required to confirm the source of the elevated concentration, however it is noted that the maximum concentration measured in RO permeate is two orders of magnitude lower than the health value for acrylonitrile and therefore the health risk is still considered low $\left(\mathrm{RQ}_{\max }=0.007\right)$. Despite the fact that $\mathrm{RO}$ rejection of bisphenol A is expected to be better than $90 \%$ (Wintgens et al. 2004; Lee et al. 2008), bisphenol A was more frequently detected in RO permeate than secondary WW, and median concentrations were similar. Other studies have also reported frequent detection of bisphenol A in RO permeate at concentrations up to $0.5 \mu \mathrm{g} / \mathrm{L}$ (Al-Rifai et al. 2011), although still significantly lower than the health value of $175 \mu \mathrm{g} / \mathrm{L}$. Bisphenol A is a very common water contaminant at $\mathrm{ng} / \mathrm{L}$ levels, sourced from polycarbonates and epoxy resins (Tsai 2006) and thus there may be a source within the water treatment process. However, the bisphenol A dataset may also have been influenced by trace bisphenol A contamination during sample collection or analysis, with detections in several field blanks in the first sampling event, which also had the highest number of detections of bisphenol A in $\mathrm{RO}$ permeate. Common routes of contamination include the presence of bisphenol A in purified laboratory water and plastic components of laboratory equipment (Watabe et al. 2004). Further sampling is therefore required to clarify the trend. 
Like the DBPs, six of the eight VOCs that were frequently detected in RO permeate (chloromethane, benzene, toluene, ethylbenzene, p-xylene and carbon disulphide) also increased in concentration during $\mathrm{MF} / \mathrm{RO}$ treatment (Rodriguez et al. 2012). As discussed previously, chloromethane is probably formed during chloramination. In contrast, benzene, toluene, ethylbenzene and p-xylene are all aromatic compounds associated with gasoline or diesel exhaust (Watson et al. 2001) or with oil refinery emissions (Scheff and Wadden 1993). KWRP is located on the site of an oil refinery and the increases during MF/RO treatment have been attributed to atmospheric exposure during MF treatment (Rodriguez et al. 2012). It is not clear whether increases in carbon disulphide, a volatile solvent with poor rejection, can also be attributed to this exposure as carbon disulphide is not normally associated with petrol-based contamination, and was also evident at BPP, which was not influenced by oil refinery omissions (Rodriguez et al. 2012).

In contrast to other frequently detected VOCs, 1,4-dichlorobenzene and tetrachloroethene did not increase in concentration during the treatment process and their frequent detection in RO permeate is again related to high frequencies of detection and concentration (27 and 5 times LOR respectively) in secondary WW, in conjunction with poor rejection by $\mathrm{RO}$ membranes. The high frequency of detection of 1,4-dichlorobenzene in secondary WW is attributed to its long history of domestic use in toilet products, moth repellents, and mildew control agents (NICNAS 2000), and relatively low biodegradation rates in WW treatment (Koe and Shen 1997). Tetrachloroethene is widely used for dry cleaning of fabrics, and its presence in WW input has been linked previously to dry cleaning activities (Rule et al. 2006). As relatively small (MW = 147 Da 1,4-dichlorobenzene, 165 Da tetrachloroethene) and uncharged molecules, with relatively high octanol-water partitioning coefficient ( $\log \mathrm{K}_{\mathrm{ow}}$ is 3.4 for both chemicals), $\mathrm{RO}$ rejection is expected to be poor to moderate (Bellona et al. 2004).

\section{Screening health risk assessment of RO permeate}


The screening health risk assessment for RO permeate assessed RQs for the 11 chemical classes summarised in Supporting Information Tables S1-S13, plus previously reported risk assessments for dioxins-like chemicals, PAHs, and gross alpha and gross beta particle activity (Rodriguez et al. 2008; Van Buynder et al. 2009). Table 3 lists all chemicals (16) for which $R_{Q_{m e d}}$ or $R Q_{\max }$ were calculated to be greater than 1. Eight of these chemicals (1 pesticide, 4 DBPs, 1 hormone, and 1 complexing agent) were never detected but had lower health values than average LOR. In many cases, these health values were very conservative and therefore elevated RQs do not necessarily constitute a health issue. For example, health values for the haloacetic acids (HAAs) and complexing agents were developed using the conservative TTC approach, all assigned a health value of $0.7 \mu \mathrm{g} / \mathrm{L}$. In comparison, health values for regulated HAAs range from $60 \mu \mathrm{g} / \mathrm{L}$ (dibromoacetic acid \& bromoacetic acid) to $150 \mu \mathrm{g} / \mathrm{L}$ (chloroacetic acid), while health values for the regulated complexing agents EDTA and NTA are 200 and $250 \mu \mathrm{g} / \mathrm{L}$ respectively. It may be expected that unregulated chemicals would have comparable toxic effects to regulated chemicals, based on similar chemical structures. For example, EDTA, NTA, diethylenetriaminepentaacetic acid (DPTA) and propylenediaminetetraacetic acid (PDTA) had no pronounced difference in impact on aquatic organisms when tested as the same metal complex (Schmidt and Brauch 2004). A less conservative approach to determine health values for these chemicals could be to divide the health value of the lowest regulated chemical (i.e. dibromoacetic acid for the HAAs, EDTA for complexing agents) by a safety factor of 10. Using this approach, all RQs would be less than 1 except for tribromoacetic acid, which had the highest LOR of all tested chemicals $(29 \mu \mathrm{g} / \mathrm{L})$.

While $17 \alpha$-ethinylestradiol does have a health-based guideline, the anticipated health risk from ethinyl estradiol is also considered low. 17 $\alpha$-ethinylestradiol is a large molecule (MW = $296 \mathrm{Da}$ ) that was never detected in secondary WW $(\mathrm{LOR}=8.0 \mathrm{ng} / \mathrm{L})$. It can be calculated that $17 \alpha-$ ethinylestradiol will always be below $1.5 \mathrm{ng} / \mathrm{L}$ in post-RO water when RO removal efficiency > $81 \%$. The RO removal of $17 \alpha$-ethinylestradiol is expected to be similar to that observed for estrone 
(96.5\%) (Van Buynder et al. 2009). Similarly the pesticide thiophanate-methyl was never detected in either secondary wastewater or post-RO water ( $\mathrm{LOR}=5.75 \mu \mathrm{g} / \mathrm{L}$ for both), and therefore the actual risk quotient for post-RO water will be below 1 assuming $\mathrm{RO}$ removal efficiency $>13 \%$, which is expected given MW $=342 \mathrm{Da}$.

Nine chemicals that were detected on at least one occasion in RO permeate also reported a RQ $>1$, although assessment of these chemicals also indicates there is a low health risk, except from a few selected $\mathrm{N}$-Nitrosamines. Only two detected chemicals had $\mathrm{RQ}_{\mathrm{med}}>1$; the complexing agent DTPA and the DBP dibromochloroacetic acid, which were both detected once only at a concentration lower than the average LOR. Additionally, health values for both chemicals were determined using the TTC approach, as previously discussed. Seven other DBPs (5 N-nitrosamines, and 2 haloacetaldehydes) had $\mathrm{RQ}_{\text {med }}<1$, but $\mathrm{RQ}_{\max }>1$, although only $N$-nitrosodimethylamine (NDMA), $N$-nitrosodi-n-propylamine (NDPA) and $N$-nitrosodi-n-bultyldiamine (NDBA) were actually detected on more than one occasion. In the context of indirect potable re-use via groundwater replenishment, it is anticipated that maximum concentrations will be smoothed by groundwater storage over months to years. The only chemical detected in more than $25 \%$ of samples with a RQ > 1 is NDMA (Table 2). However, again, the median concentration of NDMA in RO permeate was below the conservative health value of $10 \mathrm{ng} / \mathrm{L}$, and all detections were below $100 \mathrm{ng} / \mathrm{L}$, which is the guideline for NDMA included in the most recent revision of the Australian Drinking Water Guidelines (ADWG 2011). Fristachi and Rice (2007) have estimated that the proportional oral intake of NDMA attributable to the consumption of drinking water relative to other exogenous sources, such as beer or food, is $2.7 \%$, and only $0.02 \%$ when endogenous sources (created in the digestive system) are also included. Thus the majority of NDMA exposure for humans is not from drinking water consumption and the increased risk to human health from NDMA provided by drinking water consumption is still relatively minor. Our assessment of a low health risk from ROtreated WW agrees with other assessments undertaken using multiple bioassays (Van Buynder et al. 
2009; Escher et al. 2011; Macova et al. 2011). In particular, screening undertaken during the project using a cytokinesis-block micronucleus assay with a human lymphoblastoid cell-line indicated that there was no significant cytotoxicity or genotoxicity for either secondary wastewater or RO-treated wastewater (Van Buynder et al. 2009), and the toxicity of RO-treated WW has been shown to be indistinguishable from that of drinking water (Escher et al. 2011).

\section{Anthropogenic chemicals in RO permeate DOC}

The median DOC concentration measured in RO permeate was $0.2 \mathrm{mg} / \mathrm{L}$, with a maximum detected concentration of $0.6 \mathrm{mg} / \mathrm{L}$, and 10 out of 14 measurements $(64 \%)$ above or at the LOR $(0.2 \mathrm{mg} / \mathrm{L})$. However, similar concentrations of DOC were frequently measured in both field and trip blanks, both with $53 \%$ detections. Analysis of DOC by high-temperature combustion is known to be limited by detections in blank samples, and is also typically less sensitive than methods using persulphate oxidation (Clesceri et al. 1998). However, the DOC concentrations measured in this study are similar to other reported values for RO treated secondary WW, which range from 0.3 to $0.8 \mathrm{mg} / \mathrm{L}$ (Fujita et al. 1996; Drewes et al. 2003; Henderson et al. 2010). More recently online DOC measurements at a water recycling plant utilising ultrafiltration and RO, also using secondary WW from Beenyup WWTP have been found to be less than $0.05 \mathrm{mg} / \mathrm{L}$ (Pers. Comm. Water Corporation of Western Australia 2012). Online measurements will be less impacted by DOC contamination during sampling and so it is anticipated that the calculated median of $0.2 \mathrm{mg} / \mathrm{L}$ represents an upper boundary, with the actual DOC concentration of the RO permeate likely to be closer to $0.05 \mathrm{mg} / \mathrm{L}$.

Ninety-two per cent (344/375) of the chemicals monitored in this study incorporate one or more carbon atoms in their molecular structure and therefore could potentially contribute to DOC, the exceptions being inorganic anions and metals. Estimates of DOC contribution for all chemicals are reported in Tables S3-S15 (Supporting Information), while Table 4 summarises the overall contribution of the chemicals measured to DOC. If we consider all chemicals, regardless of whether 
they were ever detected in RO permeate, the sum of median DOC contributions $\left(\mathrm{DOC}_{\mathrm{med}}\right)$ was 45.8 $\mu \mathrm{g} / \mathrm{L}$ and the sum of maximum DOC contributions $\left(\mathrm{DOC}_{\max }\right.$ ) was $94.8 \mu \mathrm{g} / \mathrm{L}$. However, assessment of DOC contributions of individual chemicals indicated that over $70 \%$ of this estimate $(33.6 \mu \mathrm{g} / \mathrm{L}$ $\mathrm{DOC}_{\mathrm{med}}$ or $67.2 \mu \mathrm{g} / \mathrm{L} \mathrm{DOC}_{\max }$ ) is contributed by 16 chemicals that were never detected in $\mathrm{RO}$ permeate (13 pesticides, tribromoacetic acid, chloroacetic acid and PDTA), but have LORs greater than $2.5 \mu \mathrm{g} / \mathrm{L}$. Recalculation of the DOC without these chemicals was much lower, $12.3 \mu \mathrm{g} / \mathrm{L}$ $\mathrm{DOC}_{\text {med }}$, or $27.6 \mu \mathrm{g} / \mathrm{L} \mathrm{DOC}_{\max }$. Furthermore, the sum of DOC is reduced even further $\left(\mathrm{DOC}_{\mathrm{med}}=\right.$ $3.7 \mu \mathrm{g} / \mathrm{L}$ and $\mathrm{DOC}_{\max }=10.4 \mu \mathrm{g} / \mathrm{L}$ ) when only chemicals actually detected in RO permeate are included, with chemicals detected in more than 25\% samples (Table 2) contributing between 19$30 \%$ of this value $\left(\mathrm{DOC}_{\operatorname{med}}=0.7 \mu \mathrm{g} / \mathrm{L}\right.$ and $\left.\mathrm{DOC}_{\max }=3.1 \mu \mathrm{g} / \mathrm{L}\right)$.

Calculation of the contribution of anthropogenic chemicals to RO permeate DOC is heavily influenced by analytical LOR. However, our calculations of DOC contribution from all detected chemicals $(3.7-10.4 \mu \mathrm{g} / \mathrm{L})$ is less than half than the expected concentration of DOC in RO permeate. Given that low molecular weight acids and neutrals have been found to make up to $50 \%$ of residual DOC in RO permeate (Drewes et al. 2003), it is likely that some DOC can be attributed to the many individual chemicals that are below detection or that were not analysed.

\section{CONCLUSIONS}

Our assessment of 375 chemicals in RO-treated WW demonstrates a high degree of safety in its use as a source of potable water. The most frequently detected chemicals in RO permeate included DBPs, VOCs and complexing agents, which is in contrast to many monitoring programs that frequently focus on pharmaceuticals, personal care products and hormones. Infrequent detection and low risk assessment of these more frequently monitored chemicals is attributed to secondary WW concentrations that are typically well below health values, and high rejection by RO membranes, often as a result of size exclusion (Bellona et al. 2004; Busetti et al. 2009). 
While RO membranes are the key chemical removal barrier, our results suggest that poor rejection by RO membranes is not always the main reason for frequent detection in RO permeate. Instead, a high volume of use, such that concentrations are high in secondary WW relative to LOR (e.g., complexing agents), and the potential for chemicals to form (e.g. DBPs) or be added (e.g. acrylamide or bisphenol A) during the treatment process were more influential. These findings provide guidance to water industry practitioners to identify the most appropriate chemical suite for monitoring, as well as provide avenues to ensure further reduction of chemical detections in ROtreated WW. In particular, source protection via regulation of chemicals in primary wastewater could help to reduce frequent detections of some chemicals.

It is noted that frequent detection in $\mathrm{RO}$ permeate does not equate to a health risk, with $\mathrm{RQ}_{\max }<0.1$ for all chemicals detected in $>25 \%$ of RO permeate samples except for NDMA $\left(R_{\max }=3\right)$, dibromomethane (0.7), and benzene (0.14). Only $N$-nitrosamines, including NDMA, are considered of potential concern in RO permeate, with a few infrequent detections of NDMA, NDBA, NDPA and NMOR above health guidelines. While median concentrations were always below health values, further research and monitoring of $N$-nitrosamines including NDMA is recommended to understand their formation and degradation and further assess health risks. It is anticipated that appropriate WW treatment, optimisation of chloramine disinfection practices, or addition of ultraviolet irradiation or advanced oxidation treatment could all provide additional barriers to ensure $N$-nitrosamine concentrations are always below health values. There remain ongoing limitations in the health risk assessment of recycled water, particularly when the LOR of currently available analytical methods are not able to reach health guidelines. More fundamentally, a lack of toxicological data for some chemicals means that health guidelines must be estimated by conservative processes such as the TTC concept. In this case, toxicological assessment via 
bioanalytical tools may provide additional confidence that there is low risk from use of RO-treated WW as a potable water source.

Assessment of the contribution of anthropogenic chemicals to residual DOC in RO permeate suggests that it is a minor component of DOC in RO permeate. Only between 3.7 and $10.7 \mu \mathrm{g} / \mathrm{L}$ could be attributed from chemicals detected on at least one occasion, with the majority of this total attributed to chemicals detected in less than $25 \%$ of samples. The chemicals monitored in this study were chosen based on health risk, rather than abundance in secondary $\mathrm{WW}$, and it is possible that some high concentration but low toxicity anthropogenic chemicals further contribute. While chemicals below detection may contribute a significant component of DOC, it is likely that natural organic matter and soluble microbial products still contribute the majority of DOC to RO permeate. A more accurate assessment of the contribution of anthropogenic chemicals to RO permeate DOC would require additional fractionation of RO DOC before analysis, and this would be technically challenging and time consuming. While natural organic matter and soluble microbial products are unlikely to have inherent health risks, they can provide a source for DBP formation. The frequent detection of DBPs in RO permeate is likely to have occurred because of the reaction of chloramine with this fraction of WW organic matter.

\section{ACKNOWLEDGEMENTS}

The authors thank A. Chan and G. Chidlow (Curtin University) for their valuable assistance in analysis and method validation. This study was part of the Western Australian Premier's Collaborative Research Program "Characterising Treated Wastewater for Drinking Purposes Following Reverse Osmosis Treatment". The authors thank all project partners and especially S. Higginson and M. Handyside from the Water Corporation of Western Australia for their assistance throughout the project. Funding from ARC Linkage project LP0989326 and Curtin University is acknowledged for enabling completion of the manuscript. 
Table 1: The 13 chemical classes tested, and the number of chemicals detected at least once in RO-treated wastewater. Information about individual chemicals is provided in the Supplementary Information, Tables S1-S15, available online at: .

\begin{tabular}{lcc} 
Chemical Class & $\begin{array}{c}\text { Number of } \\
\text { chemicals }\end{array}$ & $\begin{array}{c}\text { Detected in RO- } \\
\text { treated wastewater }\end{array}$ \\
\hline Metals and metalloids & 28 & 12 \\
Pesticides & 129 & 1 \\
Halogenated disinfection by- & 32 & 24 \\
products & 9 & 8 \\
$N$-nitrosamines & 57 & 25 \\
Volatile organic compounds & 17 & 11 \\
Polyaromatic hydrocarbons & & \\
Polychlorinated dibenzo-p-dioxins, & 29 & 4 \\
polychlorinated dibenzofurans and & & 8 \\
dioxin-like poly chlorinated & 16 & 3 \\
biphenyls & 36 & 1 \\
Phenols & 3 & 0 \\
Pharmaceuticals & 4 & 3 \\
Anions & 4 & 8 \\
Estrogenic hormones & 11 & 108 \\
Complexing agents & 375 & \\
Miscellaneous & & \\
\hline Total & &
\end{tabular}


Table 2: Chemicals detected in more than $25 \%$ of all RO-treated wastewater samples, corresponding data for secondary wastewater, and a screening health risk assessment for ROtreated wastewater using median and maximum risk quotients $\left(\mathrm{RQ}_{\operatorname{med}}\right.$ and $\left.\mathrm{RQ} \mathrm{Qmax}_{\operatorname{ma}}\right) \cdot \mathrm{n}^{\circ}=$ total number of samples analysed; nd = not detected.

\begin{tabular}{|c|c|c|c|c|c|c|c|c|}
\hline \multirow[b]{2}{*}{ Chemical } & \multicolumn{3}{|c|}{ RO-treated WW } & \multicolumn{3}{|c|}{ Secondary WW } & \multicolumn{2}{|c|}{ RQ for RO-treated WW } \\
\hline & $\mathbf{n}^{\circ}$ & $\%$ Detects & $\begin{array}{c}\text { Median } \\
(\mu \mathrm{g} / \mathrm{L})\end{array}$ & $\mathbf{n}^{\circ}$ & $\%$ Detects & $\begin{array}{c}\text { Median } \\
(\mu \mathrm{g} / \mathrm{L})\end{array}$ & $\mathbf{R} \mathbf{Q}_{\text {med }}$ & $\mathbf{R} \mathbf{Q}_{\max }$ \\
\hline Bromochloromethane & 27 & 100 & 0.11 & 33 & 94 & 0.22 & 0.003 & 0.009 \\
\hline Dibromomethane & 27 & 96 & 0.13 & 33 & 94 & 0.26 & 0.2 & 0.7 \\
\hline NDMA & 27 & 93 & 0.004 & 25 & 96 & 0.016 & 0.4 & 3 \\
\hline Boron & 28 & 89 & 75 & 31 & 100 & 160 & 0.02 & 0.04 \\
\hline 1,4-Dichlorobenzene & 27 & 89 & 0.19 & 33 & 94 & 0.81 & 0.005 & 0.02 \\
\hline Acrylonitrile & 6 & 83 & 0.13 & 6 & 50 & 0.04 & 0.004 & 0.007 \\
\hline Silicon & 21 & 76 & 120 & 22 & 100 & 8800 & 0.0003 & 0.0007 \\
\hline Lithium & 28 & 75 & 0.2 & 31 & 100 & 7.6 & 0.003 & 0.07 \\
\hline Bromodichloromethane & 27 & 70 & 0.04 & 33 & 82 & 0.06 & 0.001 & 0.007 \\
\hline Chloromethane & 27 & 63 & 0.09 & 33 & 58 & 0.12 & 0.006 & 0.03 \\
\hline Chloroform & 27 & 56 & 0.14 & 33 & 85 & 0.36 & 0.001 & 0.004 \\
\hline Strontium & 28 & 54 & 0.4 & 31 & 100 & 170 & 0.0001 & 0.0005 \\
\hline EDTA & 27 & 48 & 0.5 & 27 & 100 & 145 & 0.002 & 0.01 \\
\hline 2,4-Dichlorophenol & 21 & 48 & 0.01 & 23 & 48 & 0.013 & 0.00005 & 0.0003 \\
\hline Copper & 28 & 46 & 0.2 & 31 & 100 & 7.4 & 0.0001 & 0.0008 \\
\hline Chlorate & 24 & 46 & 12.7 & 30 & 37 & 12.8 & 0.02 & 0.07 \\
\hline Dichloroacetonitrile & 24 & 46 & 0.05 & 28 & 11 & 0.02 & 0.03 & 0.25 \\
\hline Carbon disulfide & 15 & 40 & 0.02 & 16 & 81 & 0.02 & 0.00002 & 0.0002 \\
\hline Toluene & 27 & 37 & 0.13 & 33 & 15 & 0.13 & 0.0002 & 0.002 \\
\hline Zinc & 28 & 36 & 5.0 & 31 & 100 & 55 & 0.002 & 0.004 \\
\hline NTA & 27 & 33 & 0.13 & 27 & 100 & 2 & 0.001 & 0.005 \\
\hline p-Xylene & 27 & 33 & 0.13 & 33 & 0 & nd & 0.0002 & 0.0004 \\
\hline Bisphenol A & 20 & 30 & 0.01 & 19 & 17 & 0.012 & 0.00007 & 0.0002 \\
\hline Benzene & 27 & 30 & 0.08 & 33 & 24 & 0.076 & 0.08 & 0.14 \\
\hline Tetrachloroethene & 27 & 30 & 0.17 & 33 & 88 & 0.49 & 0.003 & 0.006 \\
\hline Dibromochloromethane & 27 & 30 & 0.09 & 33 & 76 & 0.19 & 0.001 & 0.005 \\
\hline 1,4-Dioxane & 21 & 29 & 0.12 & 22 & 100 & 0.51 & 0.002 & 0.01 \\
\hline Ethyl benzene & 27 & 26 & 0.07 & 33 & 0 & nd & 0.0002 & 0.0005 \\
\hline Bromoform & 27 & 26 & 0.13 & 33 & 76 & 0.15 & 0.001 & 0.003 \\
\hline
\end{tabular}


Table 3: Chemicals with a calculated risk quotient (RQ) greater than 1 in RO-treated wastewater, ordered by percentage detection. Chemicals with health guidelines estimated by the threshold of toxicological concern are denoted by TTC. $n^{\circ}=$ total number of samples analysed; LOR = limit of reporting; $\mathrm{n} / \mathrm{a}=$ not available .

\begin{tabular}{|c|c|c|c|c|c|c|}
\hline Chemical & Health value $(\mu \mathrm{g} / \mathrm{L})$ & $\begin{array}{c}\text { Average } \\
\text { LOR }(\mu \mathrm{g} / \mathrm{L})\end{array}$ & $\mathbf{n}$ & $\begin{array}{c}\% \\
\text { Detects }\end{array}$ & $\mathbf{R} \mathbf{Q}_{\text {med }}$ & $\mathbf{R} \mathbf{Q}_{\max }$ \\
\hline NDMA & 0.01 (AGWR 2008) & 0.001 & 27 & 93 & 0.4 & 3.0 \\
\hline NDPA & $\begin{array}{c}0.005 \text { (Cal DPH } \\
2007)\end{array}$ & 0.002 & 27 & 22 & 0.3 & 1.4 \\
\hline NDBA & 0.006 (IRIS 2011) & 0.004 & 27 & 11 & 0.2 & 2.1 \\
\hline Bromodichloroacetaldehyde & 0.7 (TTC) & 0.28 & 24 & 4 & 0.29 & 1.43 \\
\hline Dibromoacetaldehyde & 0.7 (TTC) & 0.24 & 24 & 4 & 0.26 & 1.26 \\
\hline Dibromochloroacetic acid & 0.7 (TTC) & 2.3 & 27 & 4 & 2.6 & 10 \\
\hline NPIP & 0.004 (OEHAA 2009) & 0.002 & 27 & 4 & 0.3 & 1.5 \\
\hline NMOR & 0.005 (OEHAA 2009) & 0.004 & 27 & 4 & 0.4 & 2.2 \\
\hline DTPA & $0.7(\mathrm{TTC})$ & 2.3 & 27 & 4 & 3.1 & 4.6 \\
\hline Thiophanate-methyl & 5 (ADWG 2011) & 5.75 & 17 & 0 & 1.15 & $\mathrm{n} / \mathrm{a}$ \\
\hline Bromochloroacetic acid & 0.7 (TTC) & 1.0 & 27 & 0 & 1.5 & $\mathrm{n} / \mathrm{a}$ \\
\hline Dichlorobromoacetic acid & 0.7 (TTC) & 1.9 & 27 & 0 & 2.7 & $\mathrm{n} / \mathrm{a}$ \\
\hline Tribromoacetic acid & 0.7 (TTC) & 29.0 & 27 & 0 & 41 & $\mathrm{n} / \mathrm{a}$ \\
\hline NEMA & 0.002 (IRIS 2011) & 0.002 & 27 & 0 & 1.0 & $\mathrm{n} / \mathrm{a}$ \\
\hline $17 \alpha$-Ethinylestradiol & 0.0015 (AGWR 2008) & 0.002 & 29 & 0 & 1.40 & $\mathrm{n} / \mathrm{a}$ \\
\hline PDTA & $0.7(\mathrm{TTC})$ & 4.4 & 27 & 0 & 6.2 & $\mathrm{n} / \mathrm{a}$ \\
\hline
\end{tabular}

Table 4: Estimates of DOC contribution from anthropogenic chemicals measured in ROtreated wastewater. Over 70\% of total DOC from all chemicals (A) was contributed by 16 chemicals that were never detected but with LOR greater than $2.5 \mu \mathrm{g} / \mathrm{L}(\mathbf{B})$. Recalculation of total DOC without these chemicals was much lower $(\mathbf{C})$. Total DOC was also calculated for all chemicals detected in RO permeate (D) and for the most frequently detected chemicals (E), as listed in Table 2.

\begin{tabular}{lccc} 
& $\begin{array}{c}\text { Number of } \\
\text { chemicals }\end{array}$ & $\begin{array}{c}\mathbf{D O C}_{\text {med }} \\
(\boldsymbol{\mu g} / \mathbf{L})\end{array}$ & $\begin{array}{c}\mathbf{D O C}_{\mathbf{m a x}} \\
(\boldsymbol{\mu g} / \mathbf{L})\end{array}$ \\
\hline A. All chemicals & 344 & 45.8 & 94.8 \\
B. Undetected chemicals with LOR $>2.5 \mu \mathrm{g} / \mathrm{L}$ & 16 & 33.6 & 67.2 \\
$\begin{array}{l}\text { C. } \text { All chemicals except undetected chemicals } \\
\text { with LOR }>2.5 \mu \mathrm{g} / \mathrm{L}\end{array}$ & 328 & 12.3 & 27.6 \\
$\begin{array}{l}\text { D. } \text { All detected chemicals } \\
\text { E. } \text { Chemicals detected in }>25 \% \text { samples }\end{array}$ & 95 & 3.7 & 10.4 \\
\end{tabular}




\section{REFERENCES}

ADWG (2011). Australian Drinking Water Guidelines 6. Canberra, National Health and Medical Research Council, Natural Resource Management Ministerial Council.

Agenson, K.O., Oh, J.I. \& Urase, T. 2003 Retention of a wide variety of organic pollutants by different nanofiltration/reverse osmosis membranes: controlling parameters of process. $J$. Membr. Sci., 225(1-2), 91-103.

AGWR (2008). Australian Guidelines for Water Recycling: Managing Health and Environmental Risks. Augmentation of Drinking Water Supplies. Canberra, Environment Protection and Heritage Council, National Health and Medical Research Council, Natural Resource Management Ministerial Council.

Al-Rifai, J.H., Khabbaz, H. \& Schafer, A.I. 2011 Removal of pharmaceuticals and endocrine disrupting compounds in a water recycling process using reverse osmosis systems. Sep. Purif. Technol., 77(1), 60-67.

Bartels, C.R., Wilf, M., Andes, K. \& Iong, J. 2005 Design considerations for wastewater treatment by reverse osmosis. Water Sci. Technol., 51(6-7), 473-482.

Bellona, C., Drewes, J.E., Xu, P. \& Amy, G. 2004 Factors affecting the rejection of organic solutes during NF/RO treatment - a literature review. Water Res., 38(12), 2795-2809.

Bolyard, M., Fair, P.S. \& Hautman, D.P. 1992 Occurrence of chlorate in hypochlorite solutions used for drinking-water disinfection. Environ Sci. Technol., 26(8), 1663-1665.

Bruce, E.D., Abusalih, A.A., McDonald, T.J. \& Autenrieth, R.L. 2007 Comparing deterministic and probabilistic risk assessments for sites contaminated by polycyclic aromatic hydrocarbons (PAHs). J. Environ. Sci. Health A, 42(6), 697-706.

Busetti, F., Badoer, S., Cuomo, M., Rubino, B. \& Traverso, P. 2005 Occurrence and removal of potentially toxic metals and heavy metals in the wastewater treatment plant of Fusina (Venice, Italy). Ind. Eng. Chem. Res., 44(24), 9264-9272.

Busetti, F., Linge, K.L. \& Heitz, A. 2009 Analysis of pharmaceuticals in indirect potable reuse systems using solid-phase extraction and liquid chromatography-tandem mass spectrometry. J. Chrom. A, 1216(31), 5807-5818.

Cal DPH. (2007). "NDMA and other nitrosamines - drinking water issues." Retrieved 2011, from http://www.cdph.ca.gov/certlic/drinkingwater/Pages/NDMA.aspx.

Choubert, J.M., Pomies, M., Ruel, S.M. \& Coquery, M. 2011 Influent concentrations and removal performances of metals through municipal wastewater treatment processes. Water Sci. Technol., 63(9), 1967-1973.

Clesceri, L.S., Greenberg, A.E. \& Eaton, A.D. (1998). Standard Methods for the Examination of Water and Wastewater, 20th edition. Washington, DC., APHA, AWWA, WEF.

Drewes, J.E., Reinhard, M. \& Fox, P. 2003 Comparing microfiltration-reverse osmosis and soilaquifer treatment for indirect potable reuse of water. Water Res., 37(15), 3612-3621.

Escher, B.I., Lawrence, M., Macova, M., Mueller, J.F., Poussade, Y., Robillot, C., Roux, A. \& Gernjak, W. 2011 Evaluation of contaminant removal of reverse osmosis and advanced oxidation in full-scale operation by combining passive sampling with chemical analysis and bioanalytical tools. Environ Sci. Technol., 45(12), 5387-5394.

Farre, M.J., Doderer, K., Hearn, L., Poussade, Y., Keller, J. \& Gernjak, W. 2011 Understanding the operational parameters affecting NDMA formation at Advanced Water Treatment Plants. $J$. Hazard. Mater., 185(2-3), 1575-1581.

Fristachi, A. \& Rice, G. 2007 Estimation of the total daily oral intake of NDMA attributable to drinking water. J. Water Health, 5(3), 341-355.

Fujita, Y., Ding, W.H. \& Reinhard, M. 1996 Identification of wastewater dissolved organic carbon characteristics in reclaimed wastewater and recharged groundwater. Water Environ. Res., 68(5), 867-876. 
Henderson, R.K., Stuetz, R.M. \& Khan, S.J. 2010 Demonstrating ultra-filtration and reverse osmosis performance using size exclusion chromatography. Water Sci. Technol., 62(12), 2747-2753.

IRIS. (2011). "US Environmental Protection Agency (USEPA) Integrated Risk Information System." Retrieved 2007 and 2008, from http://www.epa.gov/IRIS/.

Koe, L.C.C. \& Shen, W. 1997 High resolution GC-MS analysis of VOCs in wastewater and sludge. Environ. Monit. Assess., 44(1-3), 549-561.

Krasner, S.W., Weinberg, H.S., Richardson, S.D., Pastor, S.J., Chinn, R., Sclimenti, M.J., Onstad, G.D. \& Thruston, A.D., Jr. 2006 Occurrence of a new generation of disinfection byproducts. Environ Sci. Technol., 40(23), 7175-7185.

Kroes, R., Kleiner, J. \& Renwick, A. 2005 The threshold of toxicological concern concept in risk assessment. Toxicol. Sci., 86(2), 226-230.

Lee, J., Lee, B.C., Ra, J.S., Cho, J., Kim, I.S., Chang, N.I., Kim, H.K. \& Kim, S.D. 2008 Comparison of the removal efficiency of endocrine disrupting compounds in pilot scale sewage treatment processes. Chemosphere, 71(8), 1582-1592.

Linge, K., Blair, P., Busetti, F., Rodriguez, C., Handyside, M., Blythe, J., Bromley, M., Lord, O., Higginson, S., Heitz, A., Joll, C., Newby, C. \& Toze, S. 2010 Validation of dual membrane treatment for indirect potable reuse. Water J. Aust. Water Ass., 37 (6), 39-43.

Macova, M., Toze, S., Hodgers, L., Mueller, J.F., Bartkow, M. \& Escher, B.I. 2011 Bioanalytical tools for the evaluation of organic micropollutants during sewage treatment, water recycling and drinking water generation. Water Res., 45(14), 4238-4247.

Nasef, M.M. \& Hegazy, E.S.A. 2004 Preparation and applications of ion exchange membranes by radiation-induced graft copolymerization of polar monomers onto non-polar films. Prog. Polym. Sci., 29(6), 499-561.

NICNAS (2000). para-Dichlorobenzene Priority Existing Chemical Assessment Camperdown, Australia, National Industrial Chemicals Notification and Assessment Scheme.

OEHAA (2009). Air Toxics Hot Spots Risk Assessment Guidelines Part II: Technical Support Document for Cancer Potency Factors. Appendix A. Sacramento, California, California Environmental Protection Agency, Office of Environmental Health Hazard Assessment.

Oviedo, C. \& Rodriguez, J. 2003 EDTA: the chelating agent under environmental scrutiny. Quim. Nova, 26(6), 901-905.

Reemtsma, T., Weiss, S., Mueller, J., Petrovic, M., Gonzalez, S., Barcelo, D., Ventura, F. \& Knepper, T.P. 2006 Polar pollutants entry into the water cycle by municipal wastewater: a European perspective. Environ Sci. Technol., 40(17), 5451-5458.

Rodriguez, C., Cook, A., Devine, B., Van Buynder, P., Lugg, R., Linge, K. \& Weinstein, P. 2008 Dioxins, furans and PCBs in recycled water for indirect potable reuse. Int. J. Environ. Res. Public Health, 5(5), 356-367.

Rodriguez, C., Cook, A., Van Buynder, P., Devine, B. \& Weinstein, P. 2007a Screening health risk assessment of micropullutants for indirect potable reuse schemes: a three-tiered approach. Water Sci. Technol., 56(11), 35-42.

Rodriguez, C., Linge, K., Blair, P., Busetti, F., Devine, B., Van Buynder, P., Weinstein, P. \& Cook, A. 2012 Recycled water: potential health risks from volatile compounds and the use of 1,4dichlorobenzene as a treatment performance indicator. Water Res., 46, 93-106.

Rodriguez, C., Lugg, R., Van Buynder, P., Devine, B., Cook, A. \& Weinstein, P. 2010 Efficiency of RO for removal of chemical contaminants. Water J. Aust. Water Ass., 37, 64-68.

Rodriguez, C., Weinstein, P., Cook, A., Devine, B. \& Van Buynder, P. 2007b A proposed approach for the assessment of chemicals in indirect potable reuse schemes. J. Toxicol. Environ Health A, 70(19), 1654-1663.

Rule, K.L., Comber, S.D.W., Ross, D., Thornton, A., Makropoulos, C.K. \& Rautiu, R. 2006 Sources of priority substances entering an urban wastewater catchment - trace organic chemicals. Chemosphere, 63(4), 581-591. 
Scheff, P.A. \& Wadden, R.A. 1993 Receptor modeling of volatile organic-compounds.1. Emission inventory and validation. Environ Sci. Technol., 27(4), 617-625.

Schmidt, C.K. \& Brauch, H.J. 2004 Impact of aminopolycarboxylates on aquatic organisms and eutrophication: overview of available data. Environ. Toxicol., 19(6), 620-637.

Shon, H.K., Vigneswaran, S. \& Snyder, S.A. 2006 Effluent organic matter (EfOM) in wastewater: constituents, effects, and treatment. Crit. Rev. Environ. Sci. Technol., 36(4), 327-374.

Singh, S., Henderson, R.K., Baker, A., Stuetz, R.M. \& Khan, S.J. 2009 Distinguishing stage 1 and 2 reverse osmosis permeates using fluorescence spectroscopy. Water Sci. Technol., 60(8), 2017-2023.

Snyder, S.A., Adham, S., Redding, A.M., Cannon, F.S., DeCarolis, J., Oppenheimer, J., Wert, E.C. \& Yoon, Y. 2007 Role of membranes and activated carbon in the removal of endocrine disruptors and pharmaceuticals. Desalination, 202(1-3), 156-181.

Tsai, W.T. 2006 Human health risk on environmental exposure to bispheno A: a review. J. Environ. Sci. Health C, 24(2), 225-255.

Van Buynder, P., Lugg, R., Rodriguez, C., Bromley, M., Filmer, J., Blair, P., Handyside, M., Higginson, S., Turner, N., Lord, O., Taylor, P., Courtney, K., Newby, C., Heitz, A., Linge, K., Blythe, J., Busetti, F. \& Toze, S. (2009). Premier's Collaborative Research Program (2005-2008): Characterising Treated Wastewater For Drinking Purposes Following Reverse Osmosis Treatment. Technical Report, Department of Health, Western Australia.

Van den Berg, M., Birnbaum, L.S., Denison, M., De Vito, M., Farland, W., Feeley, M., Fiedler, H., Hakansson, H., Hanberg, A., Haws, L., Rose, M., Safe, S., Schrenk, D., Tohyama, C., Tritscher, A., Tuomisto, J., Tysklind, M., Walker, N. \& Peterson, R.E. 2006 The 2005 World Health Organization reevaluation of human and mammalian toxic equivalency factors for dioxins and dioxin-like compounds. Toxicol. Sci., 93(2), 223-241.

Watabe, Y., Kondo, T., Imai, H., Morita, M., Tanaka, N. \& Hosoya, K. 2004 Reducing bisphenol A contamination from analytical procedures to determine ultralow levels in environmental samples using automated HPLC microanalysis. Anal. Chem., 76(1), 105-109.

Water Corporation (2009). Water Forever: Towards Climate Resilience. Perth, Water Corporation of Western Australia.

Watson, J.G., Chow, J.C. \& Fujita, E.M. 2001 Review of volatile organic compound source apportionment by chemical mass balance. Atmos. Environ., 35(9), 1567-1584.

Wintgens, T., Gallenkemper, M. \& Melin, T. 2004 Removal of endocrine disrupting compounds with membrane processes in wastewater treatment and reuse. Water Sci. Technol., 50(5), 18.

Zenker, M.J., Borden, R.C. \& Barlaz, M.A. 2003 Occurrence and treatment of 1,4-dioxane in aqueous environments. Environ. Eng. Sci., 20(5), 423-432.

First received 1 April 2012; accepted in revised form 13 September 2012 